\title{
Improved Endothelium Dependent Vasodilation in Endurance Athletes and Its Relation With ACE I/D Polymorphism
}

\author{
Halil Tanriverdi, MD; Harun Evrengul, MD; Seyhan Tanriverdi, MD*; \\ Sebahat Turgut, VDPhD**,†, Beyza Akdağ, $\mathrm{PhD}^{\dagger+}$ \\ H. Asuman Kaftan, MD; Ender Semiz, MD
}

\begin{abstract}
Background Aerobic exercise enhances endothelium-dependent vasodilation in healthy individuals. It is thought that exercise increases nitric oxide (NO) production and decreases NO inactivation, leading to an increase in NO bioavailability. Angiotensin II and NO have important roles in maintaining vascular tone. There are polymorphisms of the angiotensin converting enzyme (ACE) gene and the presence of the deletion (D) allele has been associated with higher concentrations of circulating and tissue ACE. In this study, the relationship between endothelial function and ACE gene polymorphisms was investigated in athletes and sedentary subjects. Methods and Results The study group comprised 56 endurance athletes and 46 sedentary subjects who underwent brachial artery ultrasonographic examination. ACE insertion (I) and D allele frequencies were analyzed in all patients. Baseline brachial artery diameter and resting blood flow were similar in athletes and controls $(\mathrm{p}>0.05)$. The flow-mediated dilation (FMD) was $8.48 \pm 3.65 \%$ in athletes and $5.16 \pm 2.5 \%$ in controls $(\mathrm{p}=0.0001)$. FMD was significantly different between ACE genotypes in the athletes $(\mathrm{p}<0.0001)$ : it was higher in ACE II $(10.5 \pm 1.6 \%)$ subjects than in the DI $(8.4 \pm 2.3 \%)$ or DD $(7 \pm 1.2 \%)$ subgroups.
\end{abstract}

Conclusion Regular isotonic exercise can improve endothelium-dependent vasodilation especially in those with the ACE II genotype. (Circ J 2005; 69: 1105-1110)

Key Words: ACE I/D polymorphism; Athlete; Endothelial function; Flow mediated dilation

$\mathbf{T}$ he vascular endothelium plays an important role in the regulation of vascular tone and the maintenance of cardiovascular homeostasis! Importantly, endothelial dysfunction, particularly impaired endotheliumdependent vasodilation, has been linked to the pathogenesis of atherosclerotic vascular disease and acute cardiovascular events? Indeed, reduced endothelial vasodilatory function occurs early in atherogenesis before histological and angiographic evidence?,4

Epidemiologic studies have shown that high levels of physical activity and cardiorespiratory fitness reduce cardiovascular morbidity and mortality in the general population, including healthy subjects.5,6 It is clinically important to select the appropriate kind of exercise. Regular aerobic exercise is associated with beneficial changes in blood pressure, lipid metabolism, glucose metabolism, neurohormonal factors, body weight, and shear stress. 7.8 Although the mechanism of improvement in endothelial function during exercise has not been fully clarified, it is thought that nitric oxide $(\mathrm{NO})$ production is increased by up-regulation of endothelial NO synthase gene expression and vascular endothelial growth factor-induced angiogenesis, as well as decreased NO inactivation with augmented antioxidants,

(Received March 23, 2005; revised manuscript received June 2, 2005; accepted June 8, 2005)

Departments of Cardiology, *Radiology, **Physiology, Pamukkale University School of Medicine, Pamukkale University Research Center for Genetic Engineering and Biotechnology (PAMGEN) and †Department of Bioistatistic, Pamukkale University School of Medicine, Denizli, Turkey

Mailing address: Halil Tanriverdi, MD, Pamukkale Üniversitesi Tip Fakültesi, Kardiyoloji AD, Kinikli, Denizli,Turkey. E-mail: htanriverdi @ posta.pamukkale.edu.tr such as superoxide dismutase and glutathione peroxidase, and attenuation of nicotinamide adenine dinucleotide/nicotinamide adenine dinucleotide phosphate (NADH/NADPH) oxidase activity, all leading to an increase in NO bioavailability?

Polymorphisms of the angiotensin converting enzyme (ACE) gene, located on chromosome 17, have been found and the polymorphism is characterized by the presence (insertion (I)) or absence (deletion (D)) of a 287-base-pair alu repeat within intron 16 . The presence of the $\mathrm{D}$ allele has been associated with higher concentrations of circulating and tissue ACE. Increased ACE activity might lead to high Angiotensin II (Ang II) concentrations 10 Of the several candidate genes for endothelial dysfunction, the ACE gene appears to be a likely one because (1) it is anchored via its carboxyl terminus to the endoluminal side of the endothelial cell plasma membrane, from where it can be released in the bloodstream, $, 11,12$ and (2) the increased plasma ACE activity found in subjects with the $\mathrm{D}$ allele could decrease bradykinin bioactivity with ensuing blunting of receptormediated release of $\mathrm{NO} !^{13}$ Furthermore, even though the literature is variable on whether Ang II effects are increased in subjects with the D allele, ${ }^{14,15}$ enhanced Ang II production can increase the concentrations of superoxide through increased activity of NADH/NADPH oxidase activity ${ }^{16}$ and thus lower the bioactivity of $\mathrm{NO}^{17}$ The balance of vasodilators and vasoconstrictors also plays an important role in the physiologic regulation of vascular tone; ${ }^{18}$ However, it is not clear whether the ACE genotype can modify the endothelial response to exercise in athletes.

The aim of this study was to investigate the relationship between the ACE genotype and endothelial function in athletes and sedentary subjects by measuring flow-mediated 


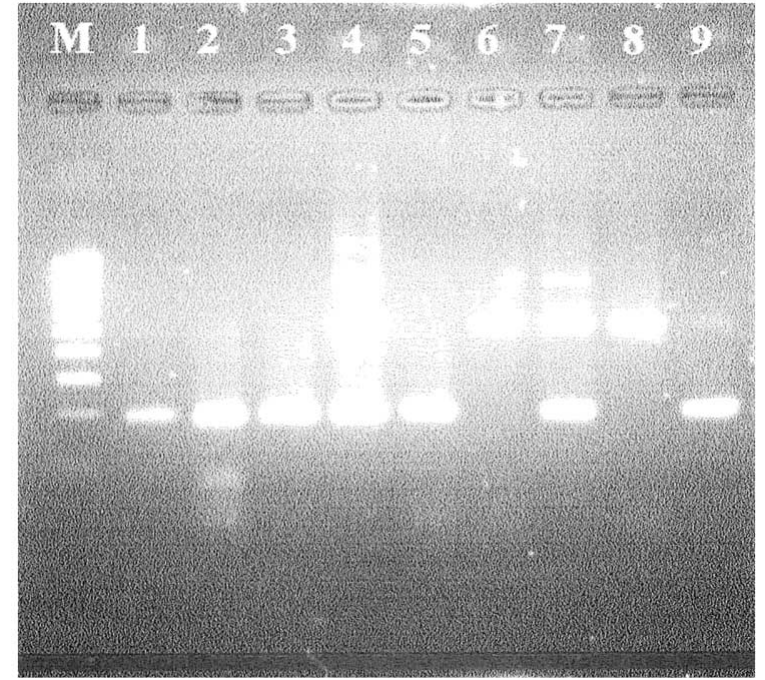

Fig 1. Polymerase chain reaction analysis of the I/D polymorphism of the angiotensin-converting enzyme. DD (lanes 1-3, 5, 9), ID (lanes 4, 7), II (lanes 6, 8), M (Marker, $100 \mathrm{bp} \mathrm{ladder).}$

dilation (FMD) in the brachial artery ultrasonographically.

\section{Methods}

\section{Subjects}

The study group comprised 56 athletes (43 men, 13 women, mean age $23 \pm 1.7$ years) and 46 sedentary subjects (36 men, 10 women, mean age $22.5 \pm 1.5$ years) who underwent vascular ultrasonographic assessment and analysis of ACE I and D allele frequencies. The athletic individuals were selected from volunteer endurance athletes (35 middle-distance running, 21 football players). All the athletes had been competing at the national or international level for several years. None of the subjects had a history of cigarette smoking, hypertension, coronary artery disease, diabetes mellitus, renal or hepatic dysfunction, or a positive family history of hypertrophic cardiomyopathy. Likewise, no medication was taken by any of the subjects for any reason, including anabolic steroids. The study was approved by the Local Ethic's Committee, and written informed consent was obtained from each participant.

\section{Lipid Parameters and ACE Genotyping}

Fasting serum samples were analyzed for total cholesterol and high-density lipoprotein cholesterol (HDL-C) by standard clinical laboratory techniques.

A total of 102 DNA samples from the athletes and controls were analyzed to determine the ACE I and D allele frequencies, and they were separated into 3 subgroups: ACE DD ( $n=46)$, DI $(n=31)$ and II $(n=25)$ genotypes.

The human ACE gene is located at chromosome 17q23 and the 287-bp ID polymorphism is located in intron 16 of the gene. Genomic DNA from the subjects was prepared from peripheral blood by standard phenol/chloroform extraction method as detailed elsewhere ${ }^{9}$ Polymerase chain reaction was used to detect the I and D alleles in intron 16 of the ACE gene according to the method described by Rigat et al ${ }^{20}$ using upstream primer 5'-CTGGAGACCACTCCCATCCTTTCT-3' and the downstream primer 5'-GATGTGGCCATCACATTCGTCAGAT-3'. Amplification was performed for 35 cycles with denaturation, extension and annealing temperatures of $94^{\circ} \mathrm{C}, 60^{\circ} \mathrm{C}$ and $72^{\circ} \mathrm{C}$, respectively. The size of the amplified fragments was determined by $2 \%$ agarose gel electrophoresis, UVI gel documentation system. A representative sample from the athletes is shown in Fig 1.

\section{Vascular Reactivity Study}

The technique for assessing endothelium-dependent and endothelium-independent vasodilation by non-invasive ultrasound has been described in detail by others ${ }^{21}$ Briefly, the diameter of the brachial artery is measured in triplicate at rest, during reactive hyperemia after administration of sublingual glyceryl trinitrate (GTN), using a high-resolution ultrasound machine with a $12.0 \mathrm{MHz}$ linear array transducer (VST-Masters, Diasonics, Santa Clara, CA, USA). Longitudinal images of the brachial artery are obtained proximal to the antecubital fossa. Transmit focus zones are set to the approximate depths of the anterior and the posterior vessel walls. Images are magnified, and the depth and gain settings are used to optimize the image of the vessel wall, in particular, the media-adventitia interface. Other investigators have demonstrated that conduit artery dilation in response to flow increase is endotheliumdependent ${ }^{22}$ whereas the dilator response to GTN is endothelium-independent ${ }^{23}$

Brachial artery ultrasound was performed in a quiet room after each patient had rested for at least $10 \mathrm{~min}$. After a baseline scan, increased flow was then induced by inflation of a pneumatic tourniquet placed around the forearm to a pressure of $300 \mathrm{mmHg}$ for $4-5 \mathrm{~min}$. A second scan was obtained 45-60s after cuff deflation. After a recovery phase of $15 \mathrm{~min}$, sublingual GTN $(0.4 \mathrm{mg})$ was administered and 3-4 min later the last scan was obtained. Vessel diameters (VD) after reactive hyperemia and GTN administration were compared to the resting diameters and expressed as a percentage of the average lumen diameter at rest, which was considered $100 \%(\mathrm{FMD} \%=[(\mathrm{VD}$ reactive hyperemia $-\mathrm{VD}$ rest $) \times$ $100] / V D$ rest; GTN\% $=[(V D$ after GTN - VD rest $) \times 100] /$ VD rest $)$. Arterial blood flow was measured as Doppler flow velocity multiplied by the cross - sectional area $\left(\pi \times \mathrm{r}^{2}\right)$.

\section{Statistical Analysis}

All analyses were performed with the SPSS 11.5 program (Chicago, IL, USA). Results are given as mean \pm standard deviation. Independent samples t-test was used for comparison of the controls and athletes. The Kruskal-Wallis test was used to test for the difference between ACE genotypes and then the Mann-Whitney U test with Bonferroni correction was used to compare the difference between each group. A p-value of $<0.05$ was considered statistically significant.

\section{Results}

\section{Basic Characteristics of the Subjects}

The characteristics of the subjects are summarized in Table 1 . There was no difference statistically between the athletes and controls ( $>>0.05$ ), according to age, gender, waist circumference, body mass index, systolic and diastolic blood pressures. As expected the heart rates of the athletes were lower than the controls $(\mathrm{p}<0.001)$.

\section{Lipid Parameters}

Concentrations of total cholesterol and high-density lipoprotein were not different statistically between athletes 
Table 1 Comparison of Group Characteristics

\begin{tabular}{lcc}
\hline \hline & Athletes $(n=56)$ & Controls $(n=46)$ \\
\hline Age $($ years $)$ & $23 \pm 1.7$ & $22.5 \pm 1.5$ \\
Gender $(\%)(M / F)$ & $76.8 / 23.2$ & $78.3 / 21.7$ \\
BMI $\left(\mathrm{kg} / \mathrm{m}^{2}\right)$ & $22.1 \pm 2.4$ & $23.6 \pm 2.4$ \\
Waist circumference $(\mathrm{cm})$ & $71.1 \pm 8.1$ & $73.5 \pm 9.5$ \\
SBP $(\mathrm{mmHg})$ & $116.8 \pm 6.5$ & $115.4 \pm 7.4$ \\
DBP $(\mathrm{mmHg})$ & $73.5 \pm 5.4$ & $72.5 \pm 4.6$ \\
Heart rate $($ beats $/ \mathrm{min})$ & $58.8 \pm 4.3$ & $71.3 \pm 9.1 *$ \\
\hline
\end{tabular}

BMI, body mass index; SBP, systolic blood pressure; DBP, diastolic blood pressure. ${ }^{*}$ For comparison of athletes, $p=0.0001$.
Table 2 Lipid Profile and Endothelial Parameters in All Study Subjects

\begin{tabular}{lcc}
\hline \hline & Athletes $(n=56)$ & Controls $(n=46)$ \\
\hline Total cholesterol $(\mathrm{mg} / \mathrm{dl})$ & $153.1 \pm 38.9$ & $158.2 \pm 35.9$ \\
HDL-C $($ mg/dl) & $45.3 \pm 11.2$ & $42.4 \pm 12.4$ \\
Brachial artery diameter $(\mathrm{mm})$ & $4.31 \pm 0.68$ & $4.36 \pm 0.65$ \\
Baseline blood flow $(\mathrm{ml} / \mathrm{min})$ & $46.4 \pm 16.5$ & $43.7 \pm 19.3$ \\
RH $(\%$ increase in flow) & $438.2 \pm 87.3$ & $424.4 \pm 99.1$ \\
Flow-mediated dilation $(\%)$ & $8.48 \pm 3.65$ & $5.16 \pm 2.5^{* *}$ \\
GTN-mediated dilation $(\%)$ & $14.48 \pm 3.8$ & $14.22 \pm 4.11$ \\
\hline
\end{tabular}

$H D L-C$, high-density lipoprotein cholesterol; $R H$, reactive hyperemia; GTN, glyceryl trinitrate. ${ }^{* *}$ For comparison of athletes, $p=0.0001$.

Table 3 Lipid and Endothelial Parameters in Athletes and Controls According to ACE Polymorphism

\begin{tabular}{|c|c|c|c|c|c|c|c|c|}
\hline & \multicolumn{8}{|c|}{ ACE genotypes } \\
\hline & \multicolumn{4}{|c|}{ Athletes $(n=56)$} & \multicolumn{4}{|c|}{ Controls $(n=46)$} \\
\hline & $D D(n=22)$ & $D I(n=18)$ & $I I(n=16)$ & $p$ value & $D D(n=24)$ & $D I(n=13)$ & $I I(n=9)$ & $p$ value \\
\hline Cholesterol $(\mathrm{mg} / \mathrm{dl})$ & $161.4 \pm 24.6$ & $170.7 \pm 38.4$ & $139.7 \pm 31.4$ & $N S$ & $144.7 \pm 32.2$ & $174.7 \pm 35.8$ & $170.3 \pm 34.7$ & 0.03 \\
\hline$H D L(m g / d l)$ & $46.2 \pm 8.2$ & $41.5 \pm 7.3$ & $48.3 \pm 12$ & $N S$ & $42.4 \pm 9.4$ & $39.5 \pm 8.8$ & $44.7 \pm 12.6$ & $N S$ \\
\hline$F M D(\%)$ & $7 \pm 1.2$ & $8.4 \pm 2.3$ & $10.5 \pm 1.6$ & 0.0001 & $4.9 \pm 1.3$ & $5.5 \pm 1.7$ & $5.5 \pm 1.9$ & NS \\
\hline$G T N-M D(\%)$ & $14.6 \pm 3.4$ & $14.2 \pm 2.8$ & $14.5 \pm 3.2$ & $N S$ & $14.2 \pm 3.9$ & $14.6 \pm 4.3$ & $14.2 \pm 4.1$ & $N S$ \\
\hline
\end{tabular}

$A C E$, angiotensin converting enzyme; $D$, deletion; I, insertion; HDL, high-density lipoprotein; FMD, flow-mediated dilation; GTN$M D$, glyceryl trinitrate-mediated dilation.

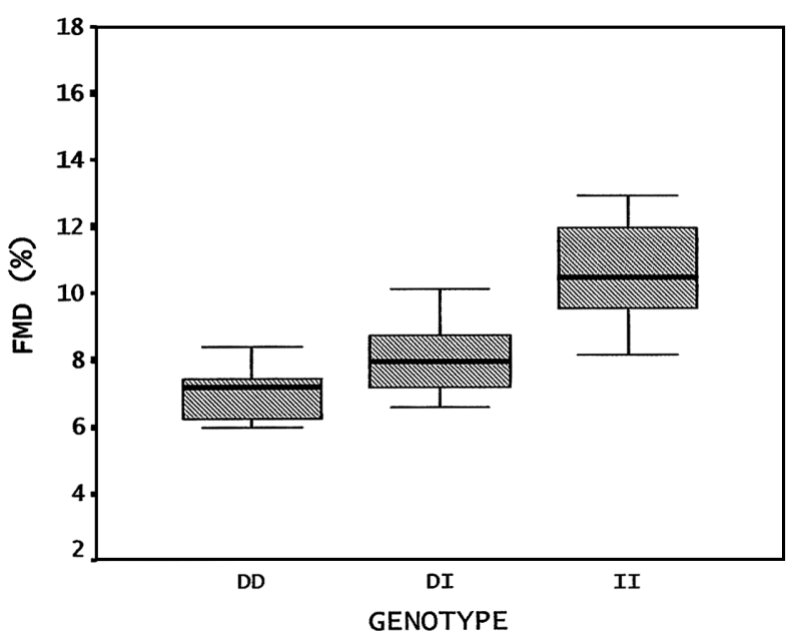

Fig 2. Box plots of flow-mediated dilation (FMD) in athletes according to the polymorphisms of the angiotensin-converting enzyme.

and controls (Table 2), and those parameters were similar in athletes and controls according to ACE genotypes (Tables 3, p>0.05).

\section{Vascular Studies}

Baseline brachial artery diameter, resting blood flow, hyperemia response, FMD and GTN-mediated dilation for athletes and controls are shown in Table 2. Baseline brachial artery diameter $(4.31 \pm 0.68$ vs $4.36 \pm 0.65 \mathrm{~mm})$, resting blood flow $(46.4 \pm 16.5 \mathrm{vs} 43.7 \pm 19.3 \mathrm{ml} / \mathrm{min})$ and the degree of reactive hyperemia by cuff inflation and release $(438.2 \pm$ $87.3 \%$ vs $424.4 \pm 99.1 \%$ ) were similar in athletes and controls $(\mathrm{p}>0.05)$. FMD was $8.48 \pm 3.65 \%$ in athletes and $5.16 \pm$ $2.5 \%$ in controls $(\mathrm{p}=0.0001)$. Dilatation in response to GTN was similar in athletes and controls $(14.48 \pm 3.8 \%$ vs $14.22 \pm 4.11 \%, \mathrm{p}>0.05)$. FMD and GTN-mediated dilation in the athletes according to ACE genotype are shown in

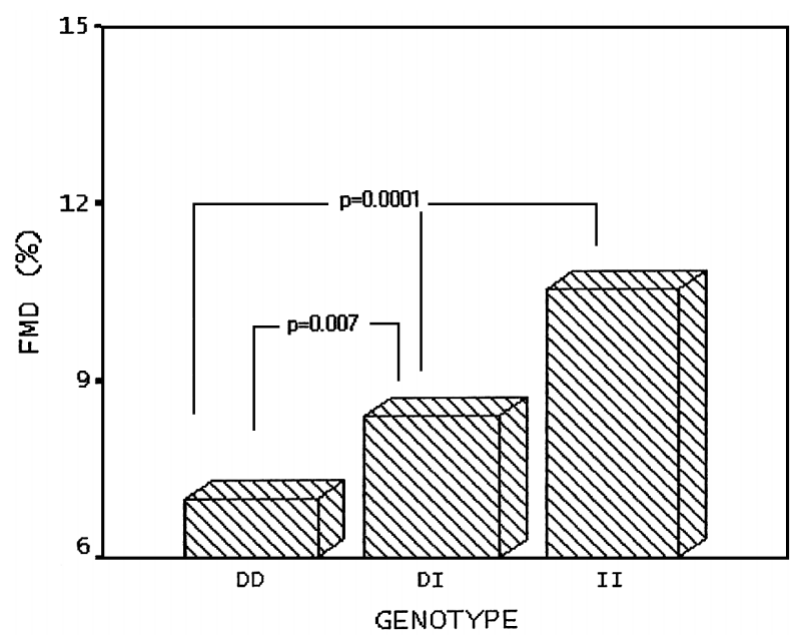

Fig 3. Comparison of flow-mediated dilatation (FMD) in athletes according to the polymorphisms of the angiotensin-converting enzyme.

Table 3. FMD differed significantly between ACE genotypes $(\mathrm{p}<0.0001)$ : it was higher in the ACE II $(10.5 \pm 1.6 \%)$ subgroup than in either the DI $(8.4 \pm 2.3 \%)$ or DD $(7 \pm 1.2 \%)$ subgroup (Figs 2,3). Dilatation in response to GTN was similar in athletes according to ACE genotypes ( $p>0.05)$. According to ACE genotype FMD and GTN-mediated dilation were not different statistically in controls (Table 3 , $\mathrm{p}>0.05$ ).

\section{Discussion}

In the present study, we evaluated the endothelial function in athletes and sedentary subjects in relation to ACE I/D polymorphism.

Healthy conduit arteries are capable of accommodating changes in blood flow by increasing their internal diameter, a phenomenon termed flow-mediated vasodilation. In vitro 
studies have shown that this physiological vessel response is endothelium-dependent 24 and that the crucial mediator is NO25 Therefore, the FMD of the brachial artery is used as an in vivo index of endothelial function ${ }^{26,27}$ because it can be induced by hyperemia and then measured non-invasively, accurately and reproducibly by high-resolution ultrasound.

\section{Exercise and Endothelial Function}

Previous animal studies suggest that exercise training improves NO-dependent vascular function and upregulates constitutive endothelial NO-synthase expression 28 Exercise programs also improve endothelium-dependent function in adults with cardiac failure, 29,30 coronary disease, 31,32 and diabetes $3^{3}$ Shear stress-mediated upregulation of NO-synthase expression, resulting from increased blood flow across the endothelium, is the likely physiologic mechanism. Acute changes in flow and shear stress stimulate the release of NO during exercise in animals, and increases in blood flow through conduit arteries are associated with flow-mediated stress on the vessel wall, which, in turn, liberates NO from the endothelium ${ }^{28}$ In humans, FMD is attenuated by coinfusion of NG-monomethyl-1-arginine, suggesting that conduit vessel dilation during exercise may, at least in part, be NO-dependent ${ }^{34}$ Improvement in vascular function in human training studies is not restricted to the vessels of the exercising musculature 29,33 and occurs in the absence of changes in lipid fractions, blood pressure, or glycemic control 35 Epidemiologic studies have demonstrated that daily physical aerobic exercise prevents cardiovascular mortality and morbidity? Physical inactivity (sedentary state) is a risk factor for cardiovascular diseases. Recent experimental studies demonstrated continued exercise-augmented vasodilation evoked by the endothelium-dependent vasodilator acetylcholine $(\mathrm{ACh})$ in dogs and rats 36 Other studies have shown that even in normal control animals ${ }^{37}$ and healthy subjects ${ }^{38}$ exercise training augments endothelial function.

There are also many human studies showing positive effects of exercise on endothelial function. Clarkson et al showed improvement in the endothelial function compared with the baseline values at the end of a 10-week exercise program in young healthy adults 39 Higashi et al found that exercise improved endothelial function in both normotensive and hypertensive subjects? In both these studies, isotonic exercise was shown to have positive effects on endothelial function. In a study done by Ebenbicher et al body-builders taking anabolic steroids and doing isometric exercise had impaired endothelial function. ${ }^{40} \mathrm{We}$ found that endothelial function was improved with long-term isotonic exercise training in athletes compared with sedentary subjects, which was in accordance with the results of Clarkson et al and Higashi et al. The beneficial effects were independent of the known influences of exercise on total cholesterol, HDL-C, or resting blood pressure.

\section{ACE Gene Polymorphism and Endothelial Function}

I/D polymorphism of the ACE gene has recently been identified as a possible risk factor for several cardiovascular disorders. Because the polymorphism is located in an intron, it is believed to be a neutral marker in strong linkage disequilibrium with one or more unknown functional variants located in or close to the ACE gene. ${ }^{41}$ The 3 genotypes include ACE DD and II homozygotes and ID heterozygotes. ${ }^{42}$ Compelling evidence indicates that the D allele of the ACE gene is related to increased plasma concentrations of ACE $10,20,41,43$

Angiotensin-converting enzyme, a key component of the circulating and vascular renin-angiotensin systems promotes the synthesis of Ang II, which is an important regulator of vascular function.4 By stimulating the AT1 receptor, Ang II promotes vasoconstriction, both directly and through endothelin release or augmentation of sympathetic tone. Moreover, increased free radical generation by Ang II may also contribute to endothelial dysfunction.4,46 In addition, ACE also metabolizes locally synthesized bradykinin, which would promote vasoconstriction by reducing bradykinin-dependent NO release. This vasoconstriction is partly inhibited by Ang II-mediated release of NO from the endothelium 47,48 Because individuals with the ACE D allele have higher plasma and tissue ACE concentrations, we hypothesized that the D allele of the ACE gene, by increasing local Ang II generation and decreasing bradykinin activity, may modulate vascular tone $!^{10,49}$

In the present study, we found no difference in endothelial function in the sedentary subjects according to ACE genotypes, as has been found in other studies50,51 According to Perticone et al, who studied a smaller population of never-treated primary hypertensive patients, the DD genotype was associated with significant blunting of endothelium-dependent vasodilation, but endothelium dependent vasodilation was normal in the healthy subjects 52 They claimed that the mechanism of forearm vasodilation in response to $\mathrm{ACh}$ in hypertensives was probably reduction of endothelium-dependent vasodilation in response to ACh infusion, or the increased breakdown of endothelium derived relaxing factor (EDRF) by the scavenger for oxygen radicals in DD homozygous subjects. It is also possible that the breakdown of bradykinin, a potent releaser of EDRF, may be involved in this effect. More recently, Butler et al reported. A blunted endothelium-dependent vasodilation in healthy young normotensive university students carrying the D allele compared with II homozygous subjects. 43 They found that the ACE gene D allele in homozygosity was associated with reduced ACh-induced vasodilation in healthy people. However, in this latter study, a blunted endothelium-independent vasodilation was also found in DD homozygous subjects, thereby suggesting that the blunted endothelium-dependent vasodilation could be in part accounted for by either a dysfunctional cGMP pathway or enhanced arteriolar structural changes, or both. Thus, their observed defect in vasomotion may not have been necessarily caused by endothelial dysfunction.

Consistent with our results, Rossi et al found no effect of the I/D genotype on the endothelium-dependent and -independent vasodilation in mild-to-moderate hypertensive and normotensive subjects ${ }^{3}$ Similarly, Celermajer et al also found no differences between D/I genotypes in the in vivo brachial artery responses of 184 normotensive nondiabetic lifelong nonsmokers using FMD ${ }^{1}$ Finally, van Dijk et al found no differences in bradykinin-induced vasodilation in 8 II and 8 DD normotensive males ${ }^{54}$ The possible explanation for these differences could reside in the different criteria used for subject enrollment. We did our best to exclude previously heavy cigarette smokers because it has been contended that the ACE genotype and smoking produce additive detrimental effects on endothelial function, although the blunting of endothelial function by smoking was not dose-dependently related to the $\mathrm{D}$ allele.

Long-term evaluation of the athletes revealed that endothelium-dependent vasodilation was better in the ACE II 
genotype subjects than in those with the DI or DD genotype. To date, there has not been a study showing the relationship between ACE I/D polymorphism and the positive effect of the exercise on endothelial function. Sanada et al researched the effect of hormone replacement therapy on endothelial function and the relationship between $\mathrm{ACE}$ gene polymorphism in postmenapausal women.55 They found that hormone replacement therapy showed more significant improvement in the subjects with II and DI genotype than in the DD genotype subjects. The effect of ACE inhibition on endothelial function in relation to the ACE genotype was investigated in hypertensive patients by Prasad et al56 who found that the improving effects of captopril therapy on endothelial function were most prominent in the D allele group, which has the highest serum concentration of the ACE enzyme. Because ACE is identical to kininase II and is present on the vascular endothelium, bradykinin is inactivated by ACE. Thus, it is assumed that ACE inhibitors may act on kininase II and increase the tissue concentration of bradykinin, which, in turn, augments the vasodilation induced by bradykinin, leading to an increase in NO synthesis $5^{57}$ They claimed that plasma ACE enzyme concentrations decreased significantly with ACE inhibitory treatment in subjects with the DD genotype, and as a result of this therapy the improvement in endothelial function was more prominent than in the other genotypes 56

It is well known that a balance between Ang II and NO is important in the regulation of vascular tone! 18,58 Ang II increases vascular superoxide production through activation of membrane-associated nicotinamide adenine dinucleotide diaphorase/nicotinamide adenine dinucleotide phosphate diaphorase oxidase, resulting in NO inactivation and toxic peroxynitrite production. Therefore, exercise may increase NO by inhibiting Ang II production. Furthermore, under physiologic conditions, endogenous bradykinin is limited by ACE. Bradykinin binds to $\mathrm{B}_{2}$ receptors on the endothelial cell surface, causing the release of NO59 Recently, Higashi and Goto have shown that plasma Ang II concentrations do not alter during aerobic exercise of mild, moderate, or high intensity in healthy young men or during exercise of moderate intensity in hypertensive patients 60,61 Therefore, it is unlikely that Ang II plays a critical role in augmentation of endothelial function during exercise training in healthy subjects. It is thought that having the $\mathrm{D}$ allele, which is associated with high plasma ACE and Ang II concentrations, contributes negatively to endothelial function, which is positively affected by the release of NO by exercise.

\section{Study Limitations}

We could not measure the serum and tissue ACE-Ang II concentrations in relation to ACE gene polymorphism, but Rigat et $\mathrm{a}^{10}$ and Butler et $\mathrm{al}^{43}$ showed that serum and tissue ACE-Ang II concentrations were increased in the presence of D allele.

\section{Conclusion}

To our knowledge, this study is the first to investigate the effects of ACE I/D genotypes on endothelial function in athletes. The results of our study indicate that endothelium-dependent vasodilation is increased by prolonged training in endurance athletes, particularly those with the ACE II genotype. However, ACE polymorphism had no effect on endothelial function in sedentary subjects.

\section{References}

1. Glasser SP, Selwyn AP, Ganz P. Atherosclerosis: Risk factors and the vascular endothelium. Am Heart J 1996; 131: 379-384.

2. Luscher TF, Tanner FC, Tschudi MR, Noll G. Endothelial dysfunction in coronary artery disease. Annu Rev Med 1993; 44: 395-418.

3. Mano T, Masuyama T, Yamamoto K, Naito J, Kondo H, Nagano R, et al. Endothelial dysfunction in the early stage of atherosclerosis precedes appearance of intimal lesions assessable with intravascular ultrasound. Am Heart J 1996; 131: 231-238.

4. Vita JA, Treasure CB, Nabel EG, McLenachan JM, Fish RD, Yeung $\mathrm{AC}$, et al. Coronary vasomotor response to acetylcholine relates to risk factors for coronary artery disease. Circulation 1990; 81: 491497.

5. Hornig BH, Maier V, Drexler H. Physical training improves endothelial function in patients with chronic heart failure. Circulation 1996; 32: 210-214.

6. Joint National Committee on Detection, Evaluation, and Treatment of High Blood Pressure. The sixth report of the Joint National Committee on Detection, Evaluation, and Treatment of High Blood Pressure (JNC-VI). Arch Intern Med 1997; 157: 2413-2446.

7. Martin JE, Dubbert PM, Cushman WC. Controlled trial of aerobic exercise in hypertension. Circulation 1990; 81: 1560-1567.

8. Paffenbarger RS, Hyde RT, Wing AL, Lee IM, Jung DL, Kampert JB. The association of changes in physical-activity level and other lifestyle characteristics with mortality among men. $N$ Engl J Med 1993; 328: $538-545$.

9. Higashi Y, Yoshizumi M. Exercise and endothelial function: Role of endothelium-derived nitric oxide and oxidative stress in healthy subjects and hypertensive patients. Pharmacol Ther 2004; 102: $87-$ 96.

10. Rigat B, Hubert C, Alhenc-Gelas F, Cambien F, Corvol P, Soubrier $\mathrm{F}$. An insertion/deletion polymorphism in the angiotensin I-converting enzyme gene accounting for half the variance of serum enzyme levels. J Clin Invest 1990; 86: 1343-1346.

11. Soubrier F, Wei L, Hubert C, Clauser E, Alhenc-Gelas F, Corvol P. Molecular biology of the angiotensin I converting enzyme. II: Structure-function: Gene polymorphism and clinical implications. $J$ Hypertens 1993; 11: 599-604.

12. Arnal JF, Battle T, Rasetti C, Challah M, Costerousse O, Vicaut E, et al. ACE in three tunicae of rat aorta: Expression in smooth muscle and effect of renovascular hypertension. Am J Physiol 1994; 267: $1777-1784$.

13. Agerholm-Larsen B, Nordestgaard BG, Tybjaerg-Hansen A. ACE gene polymorphism in cardiovascular disease: Meta-analyses of small and large studies in whites. Arterioscler Thromb Vasc Biol 2000; 20: 484-492.

14. Lachurie ML, Azizi M, Guyene TT, Alhenc-Gelas F, Menard J. Angiotensin-converting enzyme gene polymorphism has no influence on the circulating renin-angiotensin-aldosterone system or blood pressure in normotensive subjects. Circulation 1995; 91: $2933-$ 2942

15. Ueda S, Elliott HL, Morton JJ, Connell JM. Enhanced pressor response to angiotensin I in normotensive men with the deletion genotype (DD) for angiotensin-converting enzyme. Hypertension 1995; 25: $1266-1269$.

16. Griendling KK, Minieri CA, Ollerenshaw JD, Alexander RW. Angiotensin II stimulates NADH and NADPH oxidase activity in cultured vascular smooth muscle cells. Circ Res 1994; 74: $1141-$ 1148 .

17. Harrison DG. Endothelial function and oxidant stress. Clin Cardiol 1997; 20: $2-7$

18. Lüscher TF. Imbalance of endothelium-derived relaxing and contracting factors. Am J Hypertens 1990; 3: 317-330.

19. Ponez M, Solowiejczky D, Harpel B, Mory Y, Schwartz E, Surrey S. Construction of human gene libraries from small amounts of peripheral blood. Hemoglobin 1982; 6: 27-36.

20. Rigat B, Tiret L, Visvikis S, Breda C, Corvol P, Cambien F, et al. Evidence, from combined segregation and linkage analysis, that a variant of the angiotensin I-converting enzyme (ACE) gene controls plasma ACE levels. Am J Hum Genet 1992; 51: 197-205.

21. Celermajer DS, Sorensen KE, Gooch VM, Spiegelhater DJ, Miller OI, Sullivan ID, et al. Non-invasive detection of endothelial dysfunction in children and adults at risk of atherosclerosis. Lancet 1992; 340: $1111-1115$.

22. Pohl U, Holtz J, Busse R, Bassenge E. Crucial role of endothelium in the vasodilator response to increased flow in-vivo. Hypertension 1986; 8: 37-44.

23. Ludmer PL, Selwyn AP, Shook TL. Paradoxical vasoconstriction induced by acetylcholine in atherosclerotic coronary arteries. $N \mathrm{Engl}$ 
J Med 1986; 315: 1046-1051.

24. Ross R. The pathogenesis of atherosclerosis: A perspective for the 1990s. Nature 1993; 362: $801-809$.

25. Zeiher AM, Drexler H, Wollschlager H, Just H. Modulation of coronary vasomotor tone in humans: Progressive endothelial dysfunction with different early stages of coronary atherosclerosis. Circulation 1991; 83: 391-401.

26. Celermajer DS, Sorensen KE, Georgakopoulous D, Bull C, Thomas $\mathrm{O}$, Robinson J, et al. Cigarette smoking is associated with a dose dependent and potentially reversible impairment of endothelium dependent dilation in healthy young adults. Circulation 1993; 88: $2149-2155$.

27. Sorensen KE, Celermajer DS, Georgakopoulous D, Hatcher G, Betteridge DJ, Deanfield JE. Impairment of endothelium-dependent dilation is an early event in children with familial hypercholesterolemia and is related to the lipoprotein(a) level. J Clin Invest 1994; 93: $50-55$.

28. Maiorana A, O'Driscoll GJ, Taylor RR, Green DJ. Exercise and the nitric oxide vasodilator system. Sports Med 2003; 33: 1013-1035.

29. Maiorana A, O'Driscoll G, Dembo L, Cheetham C, Goodman C, Taylor R, et al. Effect of aerobic and resistance exercise training on vascular function in heart failure. Am J Physiol 2000; 279: 19992005.

30. Kobayashi N, Tsuruya Y, Iwasawa T, Ikeda N, Hashimoto S, Yasu $\mathrm{T}$, et al. Exercise training in patients with chronic heart failure improves endothelial function predominantly in the trained extremities. Circ J 2003; 67: 505-510.

31. Hosokawa S, Hiasa Y, Takahashi T, Itoh S. Effect of regular exercise on coronary endothelial function in patients with recent myocardial infarction. Circ J 2003; 67: 221 -224.

32. Hambrecht R, Wolf A, Geilen S, Linke A, Hofer J, Erbs S, et al. Effect of exercise on coronary endothelial function in patients with coronary artery disease. $N$ Engl J Med 2000; 342: 454-460.

33. Maiorana A, O'Driscoll G, Cheetham C, Dembo L, Stanton K, Goodman C, et al. The effect of combined aerobic and resistance exercise training on vascular function in type 2 diabetes. $J$ Am Coll Cardiol 2001; 38: 860-866.

34. Joannides R, Haefeli WE, Linder L, Richard V, Bakkali EH, Thuillez $\mathrm{C}$, et al. Nitric oxide is responsible for flow-dependent dilation of human peripheral conduit arteries in vivo. Circulation 1995; 91: $1314-1319$.

35. Green DJ, Walsh JH, Maiorana A, Best M, Taylor RR, O'Driscoll JG. Exercise-induced improvement in endothelial dysfunction is not mediated by changes in $\mathrm{CV}$ risk factors: Pooled analysis of diverse patient population. Am J Physiol Heart Circ Physiol 2003; 285: H2679-H2687.

36. Sessa WC, Pritchard K, Seyedi N, Wang J, Hintze T. Chronic exercise in dogs increases coronary vascular nitric oxide production and endothelial cell nitric oxide synthase gene expression. Circ Res 1994; 74: 349-353.

37. Wang J, Wolin MS, Hintze TH. Chronic exercise enhances endothelium-mediated dilation of epicardial coronary artery in conscious dogs. Circ Res 1993; 73: 829-838.

38. Green DJ, Cable T, Fox C, Rankin JM, Taylor RR. Modification of forearm resistance vessels by exercise training in young men. J Appl Physiol 1994; 77: 1829-1833.

39. Clarkson P, Montgomery HE, Mullen MJ, Donald AE, Powe AJ, Bull RNT, et al. Exercise training enhances endothelial function in young men. J Am Coll Cardiol 1999; 33: 1379-1385.

40. Ebenbichler CF, Sturm W, Gänzer H, Bodner J, Mangweth B, Ritsch $\mathrm{A}$, et al. Flow-mediated, endothelium-dependent vasodilation is impaired in male body builders taking anabolic-androgenic steroids. Atherosclerosis 2001; 158: 483-490.

41. Tiret L, Rigat B, Visvikis S, Breda C, Corvol P, Cambien F, et al. Evidence, from combined segregation and linkage analysis, that a variant of the angiotensin I-converting enzyme (ACE) gene controls plasma ACE levels. Am J Hum Genet 1992; 51: 197-205.

42. Villard E, Soubrier F. Molecular biology and genetics of the angiotensin I-converting enzyme: Potential implications in cardiovascular diseases. Cardiovasc Res 1996; 32: 999-1007.
43. Butler R, Morris AD, Burchell B, Struthers AD. DD angiotensin-converting enzyme gene polymorphism is associated with endothelial dysfunction in normal humans. Hypertension 1999; 33: 1164-1168.

44. Rosendorff $\mathrm{C}$. The renin-angiotensin system and vascular hypertrophy. J Am Coll Cardiol 1996; 28: 803-812.

45. Dohi Y, Hahn AWA, Boulanger CM, Bühler FR, Lüscher TF. Endothelin stimulated by Ang II augments contractility of spontaneously hypertensive rat arteries. Hypertension 1992; 19: 131-137.

46. Rajagopalan S, Kurz S, Münzel T, Tarpey M, Freeman BA, Griendling $\mathrm{KK}$, et al. Angiotensin II-mediated hypertension in the rat increases vascular superoxide production via membrane NADH/NADPH oxidase activation. J Clin Invest 1996; 97: 1916-1923.

47. Boulanger CM, Caputo L, Levy BI. Endothelial AT1-mediated release of nitric oxide decreases Ang II contractions in rat carotid artery. Hypertension 1995; 26: 752-757.

48. Saito S, Hirata Y, Emori T, Imai T, Marumo F. Angiotensin II activates endothelial constitutive nitric oxide synthase via AT1 receptors. Hypertens Res 1996; 19: 201-206.

49. Buikema H, Pinto YM, Rooks G, Grandjean JG, Schunkert H, van Gilst WH. The deletion polymorphism of the angiotensin-converting enzyme gene is related to phenotypic differences in human arteries. Eur Heart J 1996; 17: 787-794.

50. Anderson TJ, Elstein E, Haber H, Charbonneau F. Comparative study of ACE inhibition, Ang II antagonism, and calcium channel blockade on flow-mediated vasodilation in patients with coronary disease (BANFF study). J Am Coll Cardiol 2000; 35: 60-66.

51. Celermajer DS, Sorensen KE, Barley J, Jeffrey S, Carter N, Deanfield $\mathrm{J}$. Angiotensin-converting enzyme genotype is not associated with endothelial dysfunction in subjects without other coronary risk factors. Atherosclerosis 1994; 111: $121-126$.

52. Perticone F, Ceravolo R, Maio R, Ventura G, Zingone A, Perrotti N, et al. Angiotensin-converting enzyme gene polymorphism is associated with endothelium-dependent vasodilation in never treated hypertensive patients. Hypertension 1998; 31: 900-905.

53. Rossi GP, Taddei S, Virdis A, Ghiadoni L, Albertin G, Favilla S, et al. Exclusion of the ACE D/I gene polymorphism as a determinant of endothelial dysfunction. Hypertension 2001; 37: 293-300.

54. Van Dijk MA, Kroon I, Kamper AM, Boomsma F, Danser AH, Chang PC. The angiotensin-converting enzyme gene polymorphism and responses to angiotensins and bradykinin in the human forearm. J Cardiovasc Pharmacol 2000; 35: 484-490.

55. Sanada M, Higashi Y, Nakagawa Y, Sasaki S, Kodama I, Tsuda M, et al. Relationship between the angiotensin-converting enzyme genotype and the forearm vasodilator response to estrogen replacement therapy in postmenopausal women. J Am Coll Cardiol 2001; 37: $1529-1535$

56. Prasad A, Narayanan S, Husain S, Padder F, Waclawiw M, Epstein $\mathrm{N}$, et al. Insertion-deletion polymorphism of the ACE gene modulates reversibility of endothelial dysfunction with ACE inhibition. Circulation 2000; 102: 35-41.

57. Mombouli JV, Illiano S, Nagao T, Scott-Burden T, Vanhoutte PM. Potentiation of endothelium-dependent relaxation to bradykinin by angiotensin-converting enzyme inhibitors in canine coronary artery involves both endothelium-derived relaxing and hyperpolarizing factors. Circ Res 1995; 71: 137-144.

58. Daemen MJAP, Lombardi DM, Bosman FT, Schwarts SM. Angiotensin II induces smooth muscle cell proliferation in the normal and injured rat arterial wall. Circ Res 1991; 68: 450-456.

59. Vanhotte PM, Boulanger CM, Illiano SC, Nagao T, Vidal M, Mombouli JV. Endothelium-dependent effects of converting enzyme inhibitors. J Cardiovasc Pharmacol 1993; 22: 10-16.

60. Higashi Y, Sasaki S, Kurisu S, Yoshimizu A, Ssaki N, Matsuura H, et al. Regular aerobic exercise augments endothelium-dependent vascular relaxation in normotensive as well as hypertensive subjects: Role of endothelium-derived nitric oxide. Circulation 1999; 100: $1194-1202$

61. Goto C, Higashi Y, Kimura M, Noma K, Hara K, Nakagawa K, et al. The effect of different intensities of exercise on endothelium-dependent vasodilation in humans: Role of endothelium-dependent nitric oxide and oxidative stress. Circulation 2003; 108: 530-535. 